\title{
Industrialization of New Developments in the Lubrication System of the Coupled Tandem Mill AMEKO at ArcelorMittal Eisenhüttenstadt with Henkel AG
}

\author{
Martin Tille ${ }^{1, a^{*}}$, Benoit Staes ${ }^{2, b}$, Gaetano Sardo ${ }^{2, c}$, Andreas Müller ${ }^{1, d}$, \\ Toralf Saffer $^{1, \mathrm{e}}$, Frank Fabian ${ }^{1, \mathrm{f}}$ \\ ${ }^{1}$ ArcelorMittal Eisenhüttenstadt GmbH, Werkstraße 1, 15888 Eisenhüttenstadt, Germany \\ ${ }^{2}$ Henkel AG \& Co. KGaA, Henkelstrasse 67, 40589 Düsseldorf, Germany \\ amartin.tille@arcelormittal.com, benoit.staes@henkel.com, cogaetano.sardo@henkel.com,

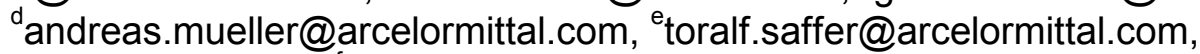 \\ frank.fabian@arcelormittal.com
}

Keywords: cold rolling, lubrication, flat steel, rolling oil

\begin{abstract}
In flat cold rolling of steels, emulsions of rolling oil and water are normally used to cool and lubricate, i.e. up to $2.5 \%$ oil is emulsified in water and sprayed on work rolls and sheet. In this article it is shown how the Henkel AG and ArcelorMittal Eisenhüttenstadt GmbH developed and industrialized successfully the thin film lubrication (TFL) in front of stand one of the AMEKO. With this device, pure rolling oil is sprayed onto the work rolls. This resulted in a rolling force decrease of approx. $4.5 \%$ in the stand and a higher operating life of the work rolls. Furthermore, the FlexMix system of the Henkel AG is presented. Therewith it shall be possible to react flexibly on the lubrication conditions in the roll gap. Using two spray bars emulsion with higher concentration is sprayed onto the strip. Trial runs were carried out in front of rolling stand number two of the AMEKO. A rolling force reduction in the stand of up to $9.7 \%$ was seen. Moreover up to $7.9 \%$ of less current could be observed on the motors of this stand. The article illustrates the theoretical and practical basics on both developments including effects on the production of the AMEKO. Further an outlook is given of how future lubrication techniques can optimize the production of flat steel cold rolling mills.
\end{abstract}

\section{Introduction}

ArcelorMittal Eisenhüttenstadt produces a wide range of cold rolled flat steel products. Approximately two third of this production is further processed in two hot dip galvanizing lines and one third in a batch annealing shop with temper rolling mill. With these production steps steel coils and sheet are produced for the automotive industry, appliances and other industrial customers in Central and Eastern Europe and Germany. Around $95 \%$ of the cold rolled production is being processed on the AMEKO; a coupled pickling tandem mill. In 2014 more than 1.17 million tons of flat products were cold rolled on that line. To meet the internal and external quality needs in terms of thickness, surface cleanliness and flatness it is essential to have an appropriate and well tuned lubrication and cooling system.

Henkel AG is a long-standing and experienced supplier of rolling oil. But since the requirements on the cold rolling process are expanding - high variety of reductions, steel grades and production constraints - the previous lubrication technique has reached its capacity limits. That is why Henkel AG not only provides rolling oils to rolling mills but also application techniques.

The tandem mill of the AMEKO has four stands of the quarto type, i.e. one pair of work rolls and one pair of back-up rolls. The maximum rolling force of each stand is currently limited to $20 \mathrm{MN}$. Moreover, the mill has positive and negative bending, a process computer und rolling pass model by ABB.

The emulsion system of the tandem mill consists of two $250 \mathrm{~m}^{3}$ tanks in the cellar. The emulsion system is necessary to cool the work rolls and the strip, to adjust the strip flatness and to lubricate 
the roll gap. By this the rolling forces are lowered and the lifetime of work rolls is enlarged. One of the two tanks donates the emulsion for the stand one to three, the other tank is for stand 4. Emulsion consists of demineralized water and rolling oil. The concentration of rolling oil in water is for stand one to three 1.5 to $2.5 \%$, for stand four 0.5 to $1.2 \%$.

The production volumes are presented in Table 1 . The table also shows the ratio of high strengths steels which can be pickled and rolled over the AMEKO. One can see that both absolute and percentaged volumes have increased over the last years.

Table 1: Yearly production at the AMEKO and the ratios of high strength steels (HSS-Ratio).

\begin{tabular}{|c|c|c|c|c|c|c|c|}
\hline \multicolumn{7}{|c|}{ Production volume and HSS-Ratio for the AMEKO } \\
\hline Year & 2009 & 2010 & 2011 & 2012 & 2013 & 2014 & 2015 \\
\hline Production [t] & 959676 & 1100192 & 1068526 & 1194759 & 1249273 & 1177493 & 825836 \\
\hline HSS-Ratio [\%] & 19.2 & 18.1 & 28.3 & 27.7 & 25.8 & 26.7 & 28.3 \\
\hline
\end{tabular}

Due to the need of weight savings of automobiles the steel industry is forced to create high strength steels grades. Thus the current and future rolling mills need more equipment than the normal emulsion system to adjust on rolling the high strength steels.

The tandem mill was built in the years 1966 till 1968. It was modernized regularly, the last modernization was the revamping of all mill drives from DC-techniques with Leonard-Transformer to state-of-the-art AC-techniques. The pickling line was put into operation in 1979. Since July 2008 both process steps have been coupled. A picture of the tandem mill is given in Fig. ${ }^{\circ} 1$.

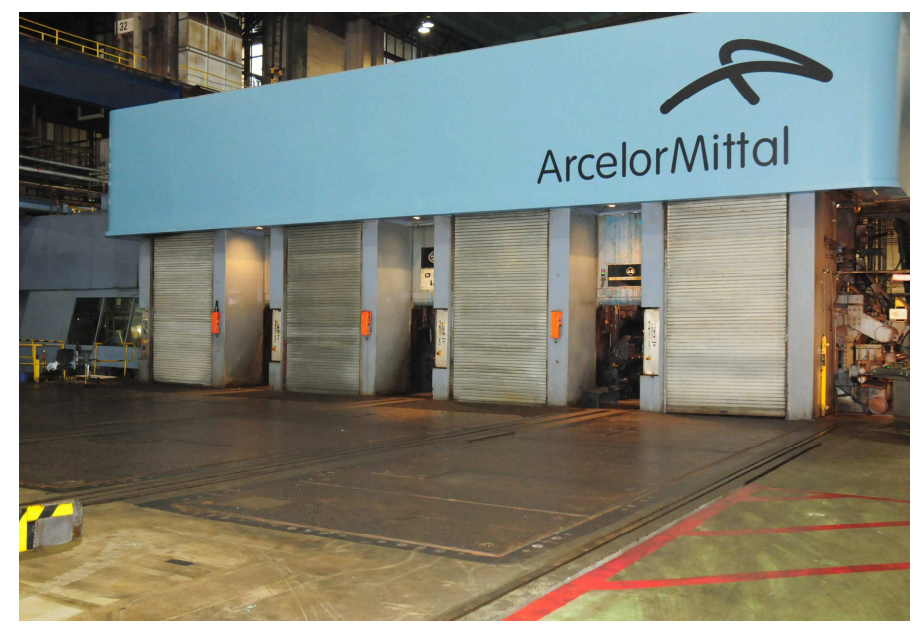

Fig. ${ }^{\circ}$ : Stand one to four of the AMEKO.

\section{TFL - Henkel's Thin Film Lubrication at ArcelorMittal Eisenhüttenstadt}

Background and Aim. After coupling the continuous horizontal pickling line with the tandem mill no pre-oiled strip was entering the mills first stand. This resulted in higher rolling force, lower lifetime of the work rolls and therewith defects both on the rolls and the strip surface - the so-called heat scratches. Finally the situation increased the energy consumption.

With the conventional actions - more entry tension, higher flow rate of emulsion or lower reduction rate no significant improvement was achieved. Thus the Henkel Rolling Oil and Application team together with cold rolling experts of ArcelorMittal Eisenhüttenstadt developed a concept in which pure rolling oil is sprayed on the work rolls. The spraying is so intense that the mechanism is comparable to an aerosol building a closed oil layer on the surface of the work rolls. 
The pursued goals were firstly reducing the rolling force in the first stand leading to a lower energy consumption. Secondly the lifetime of the work rolls should be increased. These key achievements should be achieved under the secondary condition of constant level of total rolling oil consumption of the mill.

Description of Equipment and Installation. In the years 2009 and 2010 test application equipment was installed, i.e. two spraying bars for upper and lower work roll at the entry of the first stand. When testing was ongoing the entry emulsion bars were not in operation, only the work roll cooling bars at the exit side of the stand.

After getting good results it was decided to install a permanent application solution. Fig. ${ }^{\circ} 2$ shows the basic principle of the installation and a spraying test. In the permanent solution a width and oil application quantity regulation was realized. The tool is also connected to the process computer of the mill.

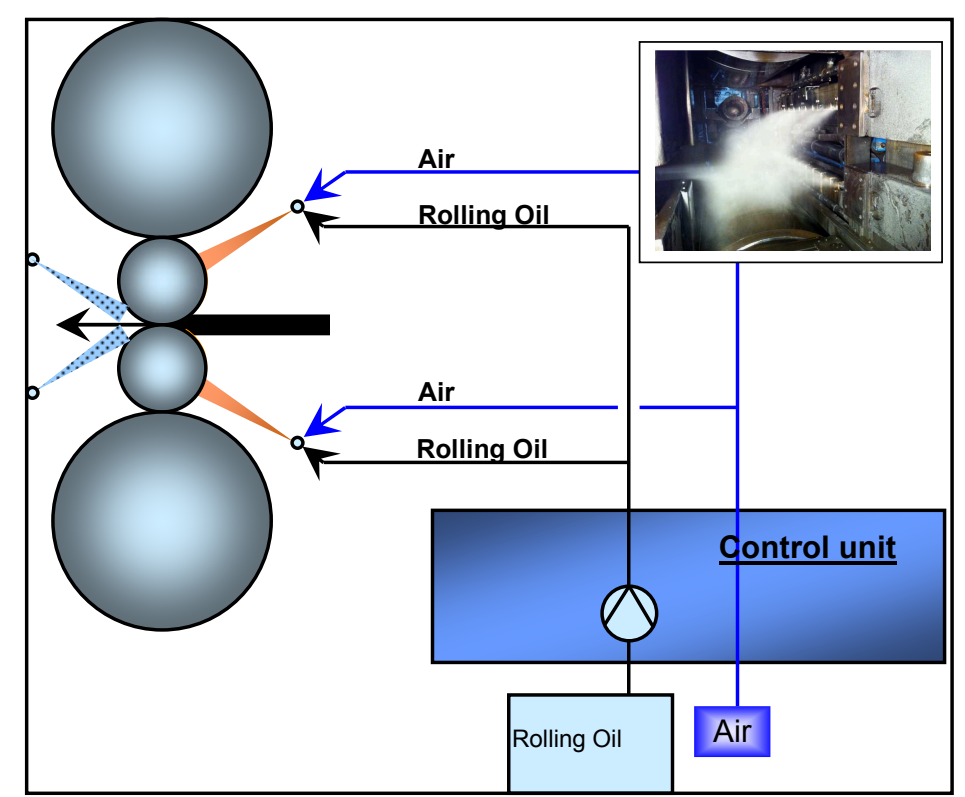

Fig. ${ }^{\circ}$ 2: TFL basic principle; the small picture shows a spraying test, when the work rolls are dismounted.

\section{FlexMix - Henkel's Flexible Lubrication at ArcelorMittal Eisenhüttenstadt}

Motivation for a new Approach. At the AMEKO there is a high variety of products, steel grades of different hardness and other constraints such as work roll changes and rolling campaigns with high requirements on strip surface quality and cleanliness. This is valid not only for the cold rolling mill in Eisenhüttenstadt but more or less for every rolling mill for flat products.

On that account quick response to the rolling process would be favorable. One step could be to adjust the lubrication to what is needed. It means to adapt the lubrication to the needs of certain rolling events. This could generate great advantages because the adaption of a conventional emulsion system is much too slow and sluggish - in terms of increasing rolling oil concentration or ingredients.

Thus it is thinkable to install FlexMix spraying bars in front of all stands to allow a maximum grade of flexibility - in terms of lubrication - in one cold rolling mill.

Description of Testing Equipment. At ArcelorMittal Eisenhüttenstadt it was decided to perform a test in front of the second stand. After the first stand the second has to execute the most deformation work. The test equipment mainly consists of three items: Tank storage, mixing station and spraying bars for both sides of the strip. The tank storage is equipped with a 1000 liter reservoir of hot demineralized water and FlexMix-rolling oil. Near the spraying bars the pipes of hot demineralized water and FlexMix-rolling oil end in a mixing station. In the mixing station a static 
mixer generates the desired composition. The spraying bars are situated over and under the strip approx. $1000 \mathrm{~mm}$ away from the entry roll gap of the second rolling stand.

The spraying bars have to be situated in a certain position from the strip and roll gap so that the lubricant can form a closed layer on the top and bottom side of the strip. The principle of the system is displayed in Fig. ${ }^{\circ}$.

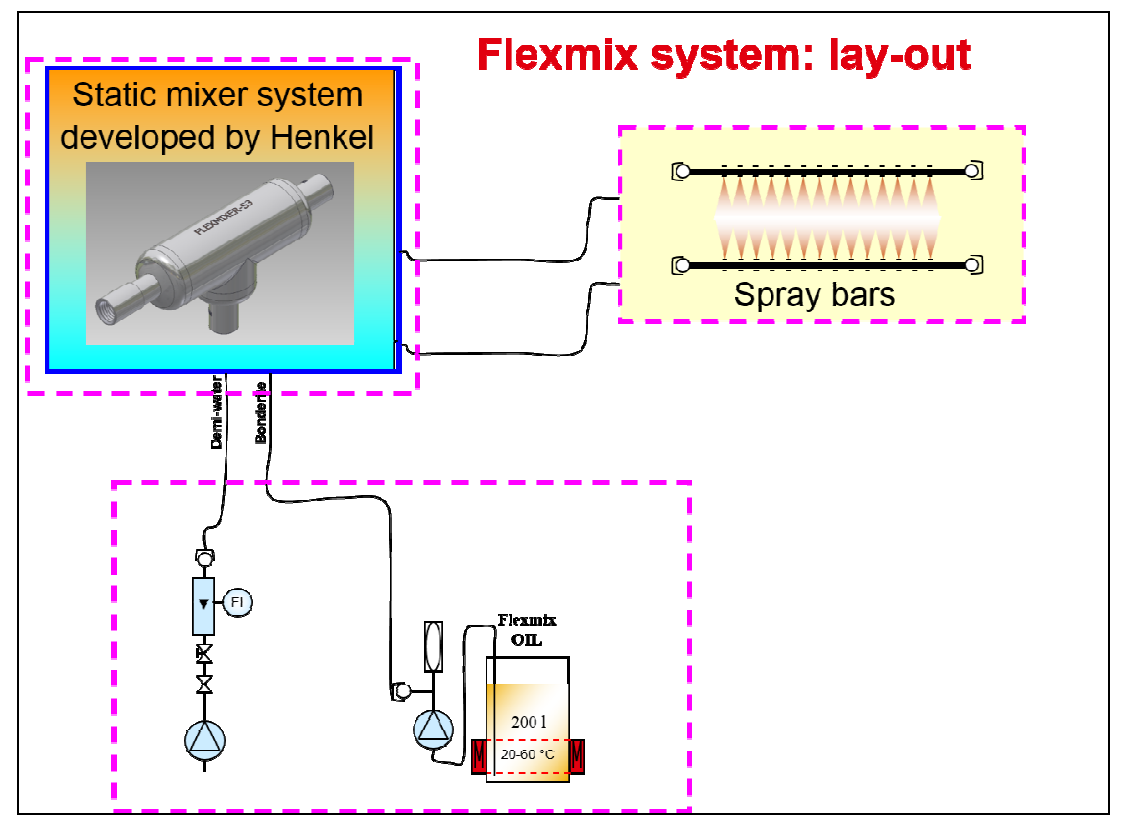

Fig. ${ }^{\circ}$ 3: Flow chart of the FlexMix equipment.

\section{Results}

Less Energy Consumption and higher Work Roll Lifetime with TFL. The aims set when installing the TFL equipment were reached. As shown in Fig. ${ }^{\circ} 4$ and Fig. ${ }^{\circ} 5$ the specific rolling energy consumption was reduced by averaged $4.5 \%$. The work roll changes could be expanded by more than $33 \%$. This was achieved without increase of total rolling oil consumption.

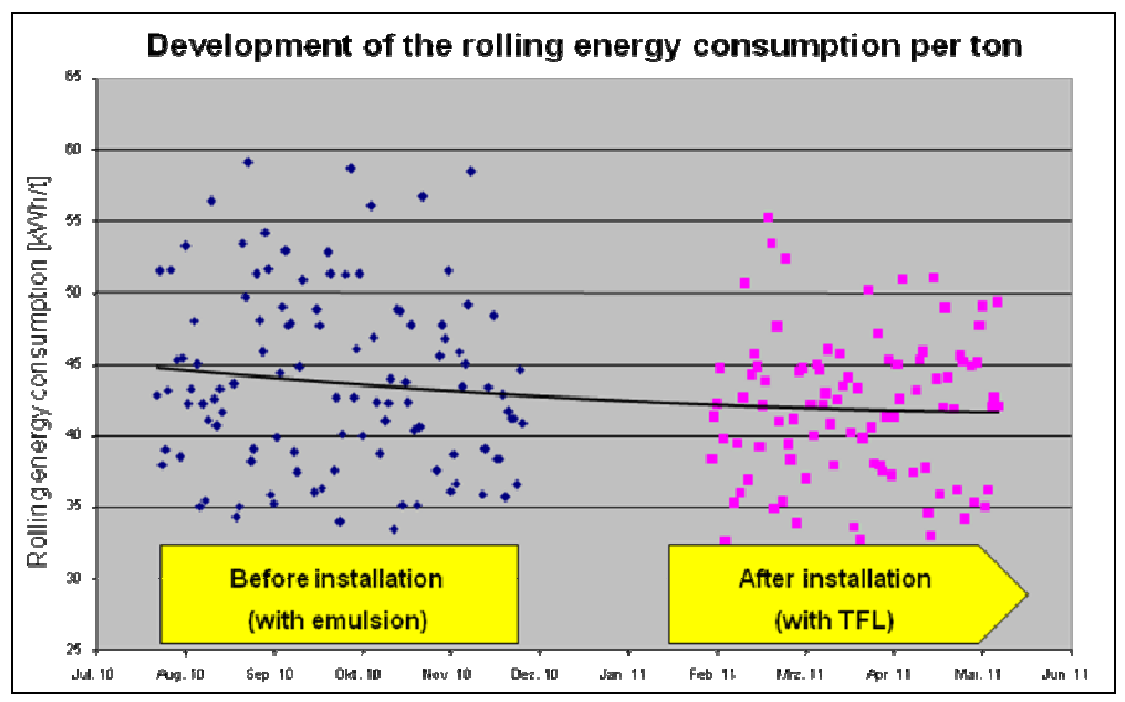

Fig. ${ }^{\circ}$ : Rolling energy consumption per ton. 


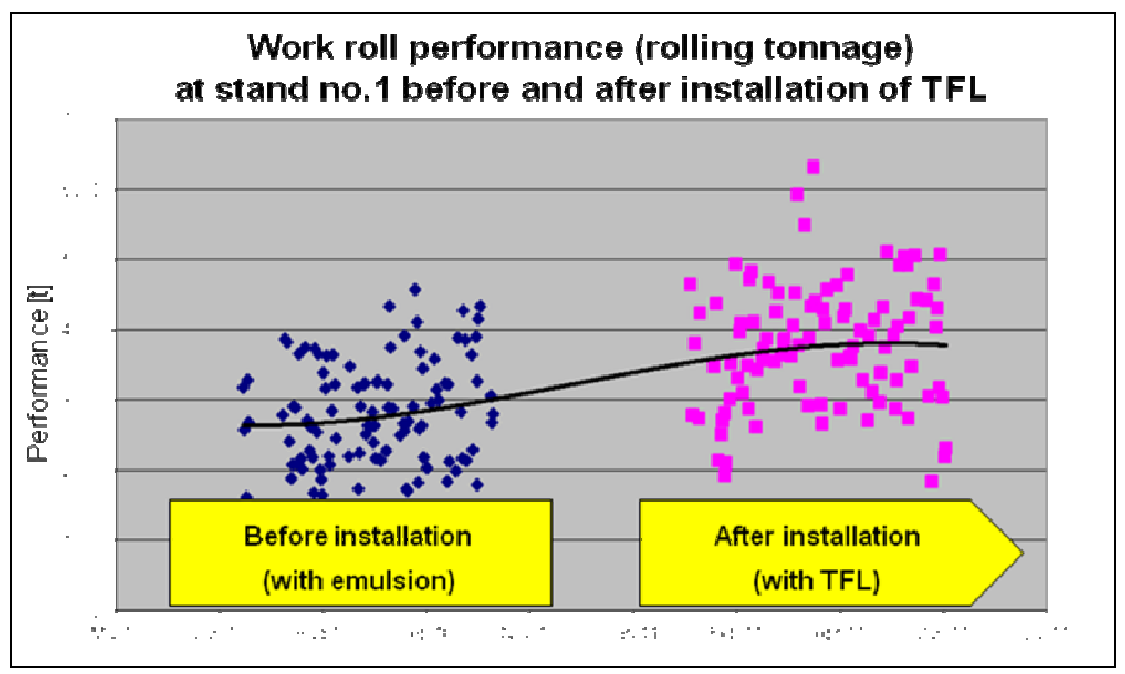

Fig. ${ }^{5}$ : Work roll usage.

After more than four years of continuous operation it can be stated that the whole application system is almost maintenance-free. Thus the first inspection was done in March 2015 with experts both from Henkel and ArcelorMittal Eisenhüttenstadt.

Up to $9.5 \%$ less Rolling Force with FlexMix. To have well comparable results FlexMix was switched off when rolling a strip in the static phase at the desired rolling speed. It is assumed that all conditions are constant in that point. Doing this the recorded values of rolling force, screw down position and drive current undergo a direct impact as one can see in Fig. ${ }^{\circ} 6$.

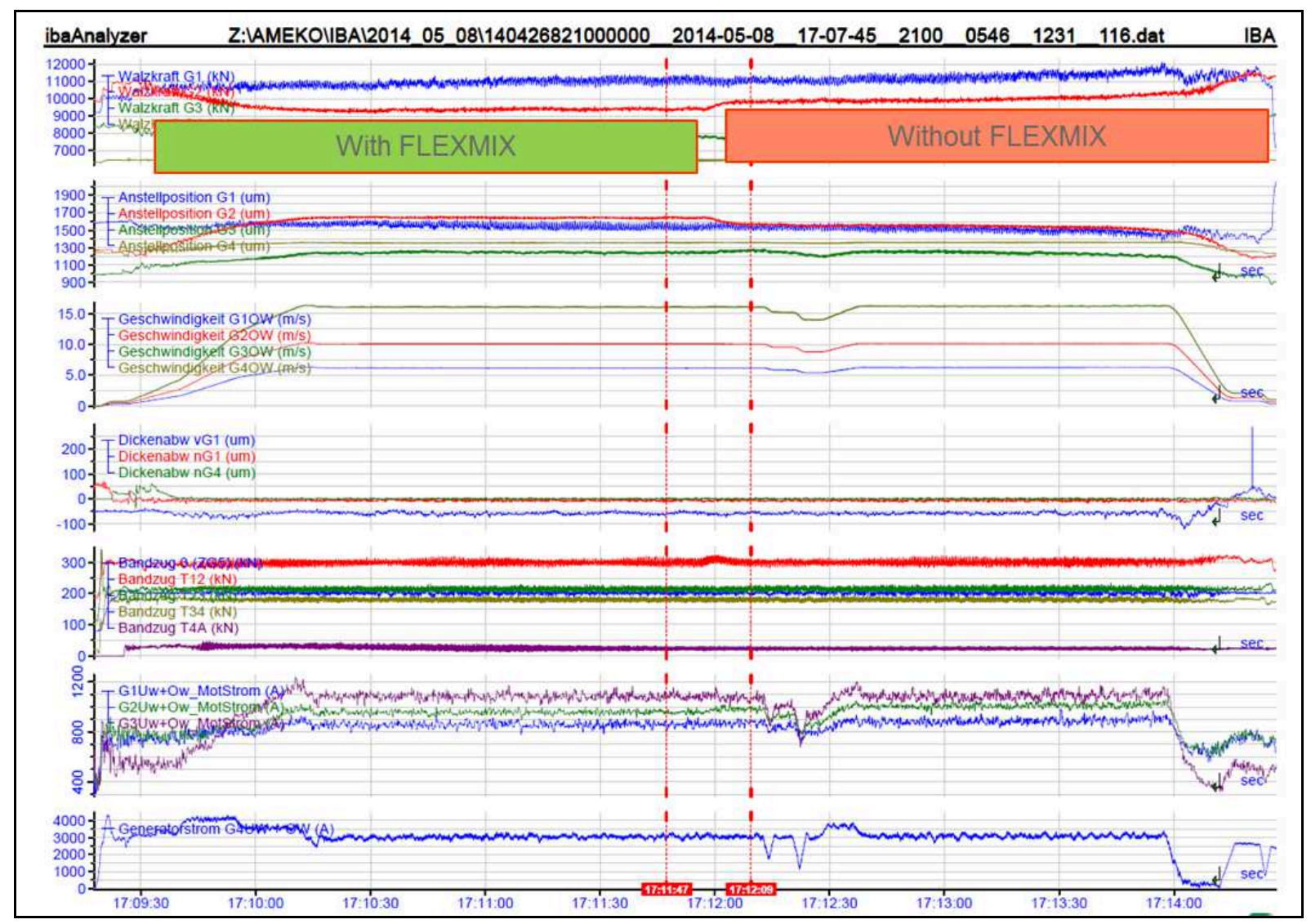

Fig. ${ }^{\circ} 6$ : The recorded values of rolling forces, positions, speed, thickness deviations, tensions, drive current of strip number 1404268210, which was produced on 08.05.2015 at the initial testing phase of FlexMix at ArcelorMittal Eisenhüttenstadt. When switching off the FlexMix spraying bars the rolling force of stand two increased from $9550 \mathrm{kN}$ to $10000 \mathrm{kN}$. 
During the first testing period the rolling force changings of stand two are presented in Table 2 . Regarding these coils an average rolling force decrease of $4.7 \%$ could be achieved.

Table 2: Running number of coils, rolling force with and without FlexMix plus the percentaged gain of rolling force decrease from the testing period of December $3^{\text {rd }} 2014$. The values were collected from the IBA-files shown above.

\begin{tabular}{|c|c|c|c|c|c|c|c|c|c|c|}
\hline \multicolumn{11}{|c|}{ Rolling force reductions with FlexMix } \\
\hline Coil-No. & 1 & 2 & 3 & 4 & 5 & 6 & 7 & 8 & 9 & 10 \\
\hline $\begin{array}{l}\text { Rolling Force with } \\
\text { FlexMix }[\mathrm{kN}]\end{array}$ & 6000 & 5938 & 6116 & 5953 & 5603 & 6400 & 5500 & 6552 & 11518 & 11510 \\
\hline $\begin{array}{l}\text { Rolling Force without } \\
\text { FlexMix }[\mathrm{kN}]\end{array}$ & 6500 & 6441 & 6709 & 6010 & 5819 & 6800 & 5756 & 6753 & 12069 & 12169 \\
\hline Gain [\%] & 8.3 & 8.5 & 9.7 & 1.0 & 3.9 & 6.3 & 4.7 & 3.1 & 4.8 & 5.7 \\
\hline Coil-No. & 11 & 12 & 13 & 14 & 15 & 16 & 17 & 18 & 19 & 20 \\
\hline $\begin{array}{l}\text { Rolling Force with } \\
\text { FlexMix }[\mathrm{kN}]\end{array}$ & 13832 & 12316 & 12957 & 11306 & 11081 & 10905 & 12302 & 12250 & 9831 & 9700 \\
\hline $\begin{array}{l}\text { Rolling Force without } \\
\text { FlexMix }[\mathrm{kN}]\end{array}$ & 14286 & 12857 & 13620 & 11718 & 11282 & 11594 & 12971 & 12750 & 10153 & 10150 \\
\hline Gain [\%] & 3.3 & 4.4 & 5.1 & 3.6 & 1.8 & 6.3 & 5.4 & 4.1 & 3.3 & 4.6 \\
\hline
\end{tabular}

\section{Summary and Outlook}

In a close partnership Henkel and ArcelorMittal Eisenhüttenstadt developed the Thin Film Lubrication from basic test equipment to a long lasting permanent installed tool. The sprayed rolling oil which becomes comparable to an aerosol bedewing the work rolls of the first stand and lead to less energy consumption and higher usage of the work rolls. These results could be achieved without an increase in rolling oil consumption. It is planned to justify and enhance the best application quantity to further improve rolling force reduction, lifetime of work rolls and rolling oil consumption.

Regarding the FlexMix concept it was proven that it has a significant influence on the rolling force at the second stand of AMEKO. It is too early to generalize the results. Moreover it has to be explained why in some cases the rolling force reduction was not as significant as expected. Another question would be how to integrate the flexible lubrication system in the conventional emulsion system without increasing the total rolling oil consumption. But even these issues would eclipse if the new approach will open new possibilities in cold rolling. Every mill is forced to overcome a lot of constraints and to expand their product range either in reduction, quality or rolling high strength steel. Further results and more comprehensive tests will be necessary to bring Henkel's FlexMix to the same successful condition like the TFL. 